\title{
A Study On The Detection Performance According To The Installation Conditions Of The Vibration Simulator
}

\author{
Soon-Young, Kwon, Seung-yeol Lee, Eun-ji Jang, In-Ho Ryu* \\ ${ }^{1}$ Korea Chamber of Commerce and Industry HRD, Gyeong-gi, 10901, Kore \\ ${ }^{2}$ Korea Chamber of Commerce and Industry HRD, Inchon, 21634, Kore \\ ${ }^{3}$ Korea Chamber of Commerce and Industry HRD, Gyeong-gi, 10901, Kore \\ ${ }^{4}$ Department of IT Applied System Engineering, Chonbuk National University, Jeonju, 54896, Korea \\ *Corresponding author.; Email address: toto00@jbnu.ac.kr
}

Article History:Received:11 november 2020; Accepted: 27 December 2020; Published online: 05 April 2021

\begin{abstract}
Vibration measurement and diagnosis technologies are widely applied for preventive maintenance that monitors the condition of facilities and conduct repairs before the occurrence of failures by identifying signs of failure. In order to train vibration measurement and diagnosis, the vibration simulators are commonly used to measure and analyze the vibration to determine abnormalities of facilities. In this paper, analyze the correlation of installation conditions on measurement performance of vibration simulator, various installation conditions and abnormal phenomena were measured through experiments and the results were analyzed and the correct installation conditions are suggested.
\end{abstract}

Keywords: Vibration simulator, Installation condition, Detection performance, Vibration diagnosis

\section{Introduction}

Many of the industrial equipment are composed of rotating equipment such as motors and pumps. In many case, rotating equipment are in charge of important processes of industrial facilities, effective maintenance is required because huge damage can occur in case of failure due to defects or damage.

As for the maintenance method, break-down maintenance, which repairs it after a breakdown occurs, is used in only few facilities that have little effect due to the breakdown or are quick to recover because the damage caused by the facility shutdown is large and it takes a lot of time to restart. The most preferred maintenance method in the field is Preventive Maintenance, which performs maintenance before actual failure occurs. Preventive maintenance is classified into time based maintenance (TBM) and Condition based maintenance (CBM). [1] TBM is a method of setting the life of parts of equipment and replacing parts according to the replacement time. However, there are problems such as excessive maintenance, such as replacing parts that can operate normally, and a decrease in operation rate due to frequent maintenance time of facilities for replacing parts with different life spans. [2] CBM can compensate for the disadvantages of TBM because it performs maintenance according to the condition of the facility. However, it is difficult to detect defects in the initial stage because it is difficult to grasp the problems of the facility below the criteria for determining the condition. Predictive maintenance to complement the shortcomings of CBM can reduce unnecessary maintenance costs by monitoring the condition of the facility in real time, detecting abnormalities early, predicting failures, and taking appropriate measures, and improving the safety and reliability of the facility. Because it can be increased, related research is being conducted very actively. [3][4]

There are several ways to measure the condition of a facility. The measurement method using sound is greatly affected by the ambient noise in the industrial site. However, the measurement method using vibration is most commonly used because it is easy to measure the condition because it measures the vibration generated by the facility itself. [5]

Research on equipment diagnosis using vibration is mainly focused on analysis of occurrence phenomena. In particular, the difference between rigid coupling and pin-type flexible body coupling is analyzed as a connection method between a motor and a shaft in order to analyze the characteristics of the vibration generated when the vibration simulator is misaligned and the vibration characteristic that occurs during the misalignment. In particular, the difference between rigid coupling and pin-type flexible body coupling is analyzed as a connection method between a motor and a shaft in order to analyze the characteristics of the vibration generated when the vibration simulator is misaligned and the vibration characteristic that occurs during the misalignment. [6] Research related to coupling, such as analysis of vibration components generated when parallel misalignment in a system connected by shaft and rigid coupling. [7] Studies have been conducted on a fault diagnosis expert system including a mechanical diagnosis algorithm capable of analyzing unbalanced mass, shaft alignment errors, oil wheel and bearing defects. [8] Recently, studies on fault diagnosis using machine learning algorithms are also actively being conducted. [9][10]

The vibration simulator is optimally set by the manufacturer and installed at the training site. However, there are many cases where the frequency characteristics do not appear depending on the installation conditions.

Therefore, in this paper, a vibration simulator installation guide was presented to enable the smooth

*Corresponding author: In-Ho Ryu

590

Department of IT Applied System Engineering, Chonbuk National University, Jeonju, 54896, Korea

Email address: toto00@jbnu.ac.kr 
instruction of educators in the educational field by analyzing the cause of the frequency characteristic not appearing for the abnormal phenomenon of the vibration simulator in the educational field and reproducing it.

\section{Analysis of vibration simulator characteristics}

In this paper, FFT (Fast Fourier Transform) is used to determine the state of equipment, and FFT uses a technique that extracts features from the measured data in the time domain in the frequency domain. The FFT algorithm makes use of the following versions, which apply equally to real or complex time series [11]:

$$
\begin{aligned}
& X(m)=\Delta t \sum_{n=0}^{N-1} x(n \Delta t) \exp ^{-j 2 \pi m \Delta f n \Delta t} \\
& x(n)=\Delta f \sum_{n=0}^{N-1} x(m \Delta f) \exp ^{j 2 \pi m \Delta f n \Delta t}
\end{aligned}
$$

These equations give the spectrum values $X(\mathrm{~m})$ at the $\mathrm{N}$ discrete frequencies $\mathrm{m} \Delta \mathrm{f}$ and give the time series $\mathrm{x}(\mathrm{n})$ at the $\mathrm{N}$ discrete time points $\mathrm{n} \Delta \mathrm{t}$

In order to, analyze the characteristics according to the installation conditions of the vibration simulator, when it is installed on the floor, which is the most ideal installation condition of the vibration simulator and when it is installed on a work bench that is generally seen in education sites, as shown in [Figure 1]. The specifications and experimental conditions of the device used in this experiment are shown in [Table 1].

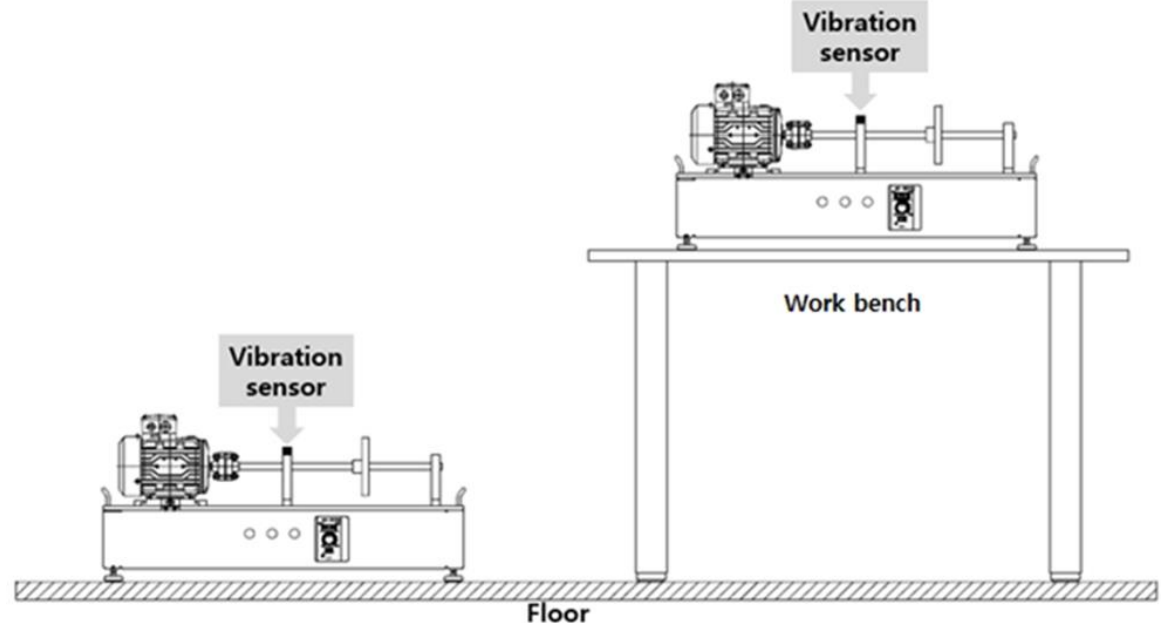

Figure 1 Vibration Simulator Set-up case (Floor \& Work bench)

Table 1 Specification of experimentation equipment

\begin{tabular}{|c|c|}
\hline Data Acquisition & $\begin{array}{l}\text { Iotech } 650 \mathrm{U} \\
\text { - USB or Ethernet interface } \\
\text { - } 5 \text { analog inputs, } \pm 40 \mathrm{~V} \text { input range } \\
\quad( \pm 60 \mathrm{~V} \text { max without damage }) \\
\text { - } 2.1 \mathrm{~mA} \text { IEPE current source per channels } \\
-1-4(22 \mathrm{~V} \text { compliance }) \\
-0.1 \mathrm{~Hz} \text { high-pass filter }\end{array}$ \\
\hline Tri-axial Vibration sensor & $\begin{array}{l}\text { Hansford HS-100s } \\
\text {-Excitation Voltage: } 18 \text {-30Volts DC } \\
\text {-Electrical Noise: } 0.1 \mathrm{mg} \max \\
\text {-Current Range: } 0.5 \mathrm{~mA} \text { to } 8 \mathrm{~mA} \\
\text {-Bias Voltage: } 10 \text { - } 12 \text { Volts DC } \\
\text {-Settling Time: } 2 \text { seconds } \\
\text {-Output Impedance: } 200 \text { Ohms max. } \\
\text {-Case Isolation : >108 Ohms at } 500 \text { Volts }\end{array}$ \\
\hline Induction motor & $\begin{array}{l}\text { Hyosung, SX0304211 } \\
\text {-Frame: } 71 \mathrm{M} \\
\text {-output power: } 0.4 \mathrm{~kW} \\
\text {-Frequency: } 60 \mathrm{~Hz}\end{array}$ \\
\hline
\end{tabular}

\section{Test equipment}




\begin{tabular}{ll}
\hline & -Voltage: $220 / 380 \mathrm{~V}$ \\
& -Duty: const. \\
& -Isolation class : F \\
\hline & MX-9000A \\
Inverter & -input voltage: AC220V, $50 \sim 60 \mathrm{~Hz}$ \\
& -output frequency: $1.0 \sim 120 \mathrm{~Hz}$ \\
& -output type: $\varnothing 3$, sine wave \\
\hline
\end{tabular}

In this paper, the natural frequency of the work bench was measured through bump test, and the installation conditions of the vibration simulator were divided into floor and work bench, and the effects of the installation conditions on the normal state, mass unbalance state and axial misalignment state were analyzed. Analysis was performed and the experimental conditions are shown in [Table 2].

Table 2 The experimentation case

\begin{tabular}{|c|c|c|c|c|}
\hline Case of experimentation & & $\begin{array}{c}\text { Simulator on } \\
\text { the Floor }\end{array}$ & $\begin{array}{c}\text { Simulator on } \\
\text { the Work } \\
\text { bench }\end{array}$ & $\begin{array}{c}\text { Work bench } \\
\text { only }\end{array}$ \\
\hline Bump test & & $x$ & $x$ & $\mathrm{O}$ \\
\hline Normal state & & $\mathrm{O}$ & $\mathrm{O}$ & $x$ \\
\hline \multirow{4}{*}{ Mass unbalanced state } & $2.5[\mathrm{~g}]$ & $\mathrm{O}$ & $\mathrm{O}$ & $x$ \\
\hline & $3.0[\mathrm{~g}]$ & $\mathrm{O}$ & $\mathrm{O}$ & $x$ \\
\hline & $4.0[\mathrm{~g}]$ & $\mathrm{O}$ & $\mathrm{O}$ & $x$ \\
\hline & $5.0[\mathrm{~g}]$ & $\mathrm{O}$ & $\mathrm{O}$ & $x$ \\
\hline \multirow{4}{*}{ Axial misaligned state } & $0.62[\mathrm{~mm}]$ & $\mathrm{O}$ & $\mathrm{O}$ & $\times$ \\
\hline & $1.25[\mathrm{~mm}]$ & $\mathrm{O}$ & $\mathrm{O}$ & $x$ \\
\hline & $1.87[\mathrm{~mm}]$ & $\mathrm{O}$ & $\mathrm{O}$ & $x$ \\
\hline & $2.50[\mathrm{~mm}]$ & $\mathrm{O}$ & $\mathrm{O}$ & $x$ \\
\hline
\end{tabular}

\subsection{Normal state result analysis}

As shown in [Figure. 2] (a), the vibration velocity value (RMS, mmps) of the vibration simulator installed on the floor is measured around $0.10[\mathrm{~mm} / \mathrm{s}]$ for both $\mathrm{x}, \mathrm{y}$ and $\mathrm{z}$ axes, so there is no mass unbalance or axial misalignment. It was determined as the normal state.

However, the vibration value measured by the vibration simulator installed on the work bench under the same conditions as the floor is shown in [Figure. 2] (b), it was confirmed that the $x$-axis increased to 4 times $(0.41[\mathrm{~mm} / \mathrm{s}])$ and the $\mathrm{Z}$ axis increased to about 6 times $(0.63[\mathrm{~mm} / \mathrm{s}])$. From this result, it was confirmed that the conditions to be installed on the work bench affect the $\mathrm{x}$ and $\mathrm{z}$ axes.

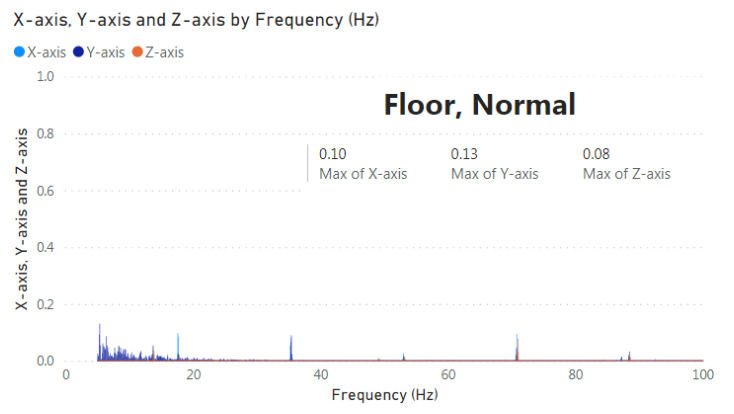

(a) Floor, Normal condition

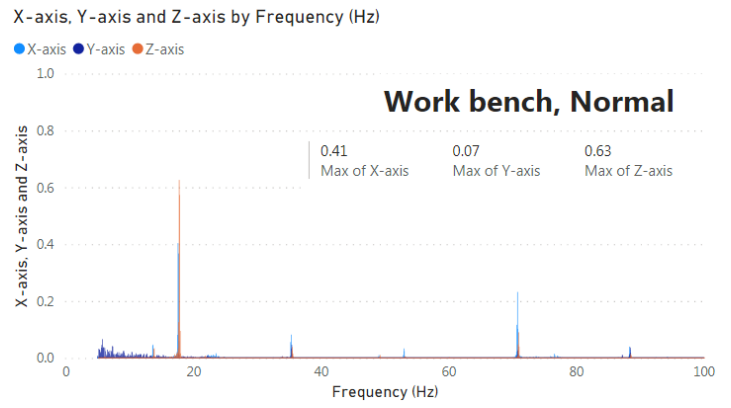

(b) work bench, Normal condition

Figure 2 Results of Vibration measurement in unbalance state(@ Floor set-up)

\subsection{Unbalanced state result analysis}

The experiment of the mass unbalanced state of the vibration simulator was measured for four mass unbalance conditions. Divided into $2.5[\mathrm{~g}], 3[\mathrm{~g}], 4[\mathrm{~g}]$, and $5[\mathrm{~g}]$, they were attached to the same position of the vibration simulator rotating disk.

As shown in [Figure 3] (a)(b)(c)(d), vibration simulator installed on the floor, the frequency of 1x, the main 
component, is $17.5 \mathrm{~Hz}$, and when the mass increases at the same frequency, the speed value of the $\mathrm{x}$-axis increases by $94 \%$ and the $y$-axis increases by $57 \%$ and the $\mathrm{z}$-axis fluctuates within \pm 0.02 .

From the measurement results, it was confirmed that $1 \mathrm{x}$, which is the main component, is $17.5 \mathrm{H}$ in the mass unbalanced condition, and the increase in the unbalanced mass has the greatest effect on the $\mathrm{x}$-axis component.

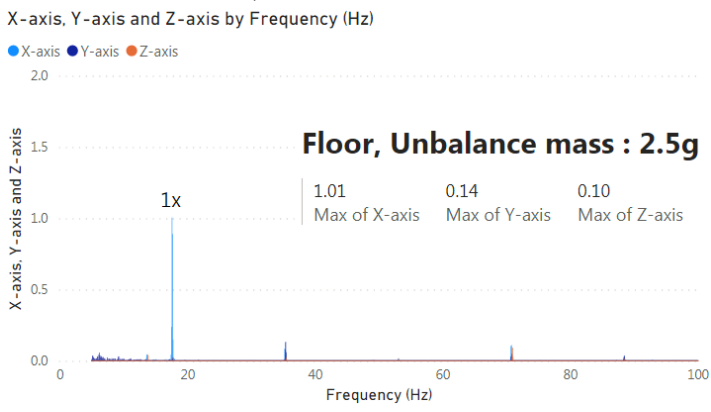

(a) Unbalance mass $[2.5 \mathrm{~g}]$

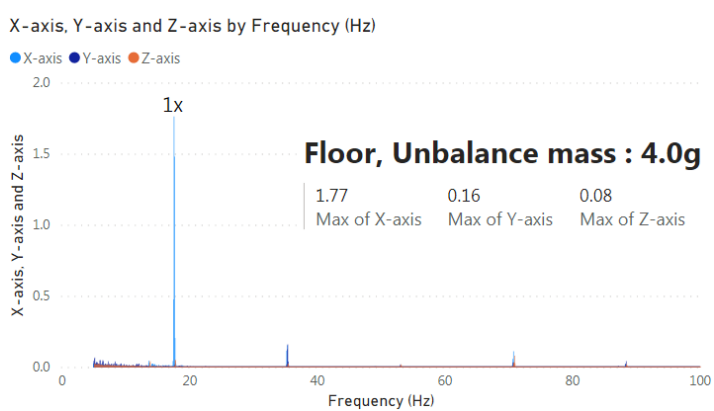

(c) unbalance mass $[4.0 \mathrm{~g}]$

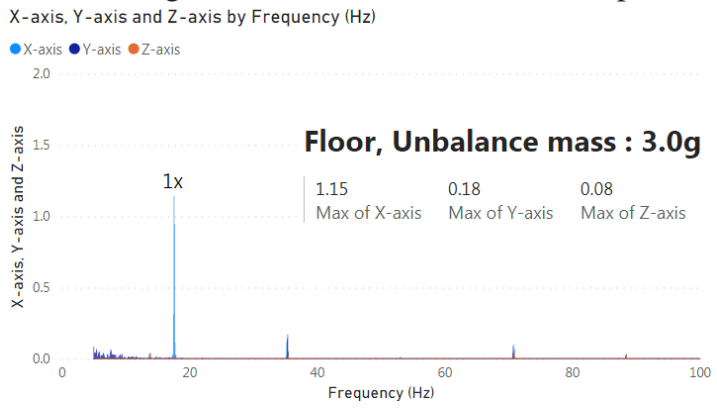

(b) unbalance mass $[3.0 \mathrm{~g}]$

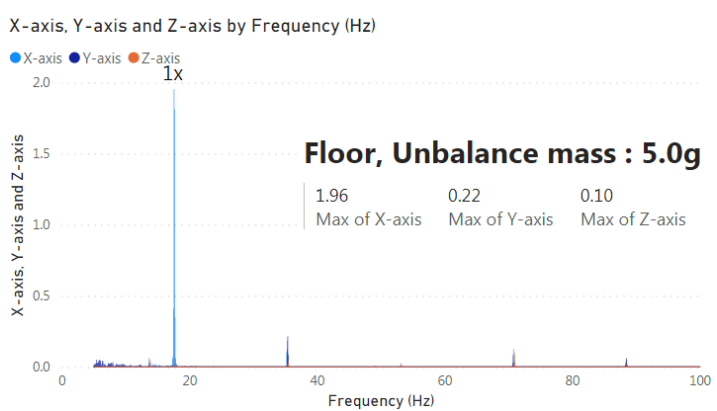

(d) unbalance mass $[5.0 \mathrm{~g}]$

Figure 3 Results of Vibration measurement in unbalance condition (@ Floor set-up)

The analysis result of the vibration simulator installed on the work bench is shown in [Figure 4], it was confirmed that the frequency of main component $1 \mathrm{x}$ was $17.5 \mathrm{~Hz}$ and same as the Floor, and as the unbalanced mass increased, the $\mathrm{x}$-axis increased by $73 \%$, the $\mathrm{y}$-axis by $102 \%$, and the $\mathrm{z}$-axis by $81 \%$. Through this, it was confirmed that the work bench has an effect on the increase of the measured values of the $\mathrm{x}, \mathrm{y}$, and $\mathrm{z}$ axes.

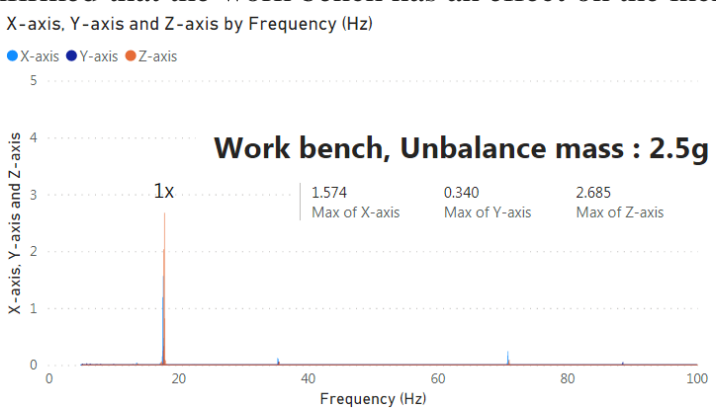

(a) Unbalance mass $[2.5 \mathrm{~g}]$

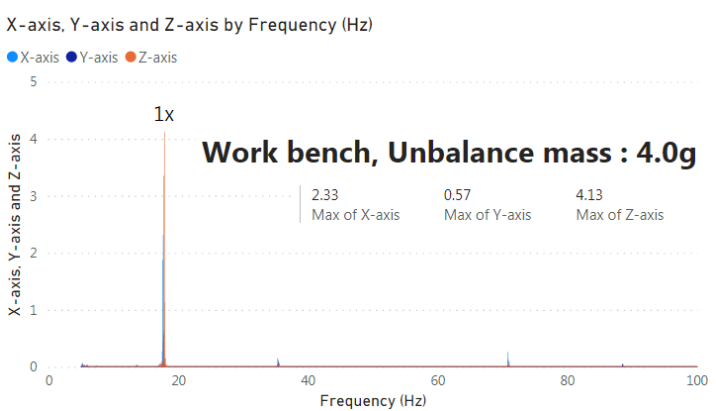

(c) unbalance mass $[4.0 \mathrm{~g}]$

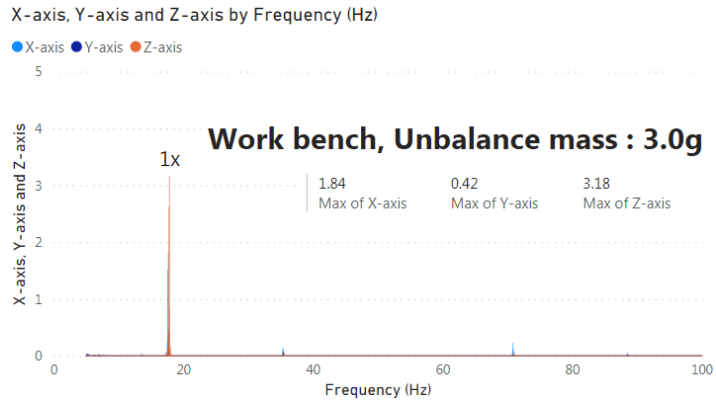

(b) unbalance mass $[3.0 \mathrm{~g}]$

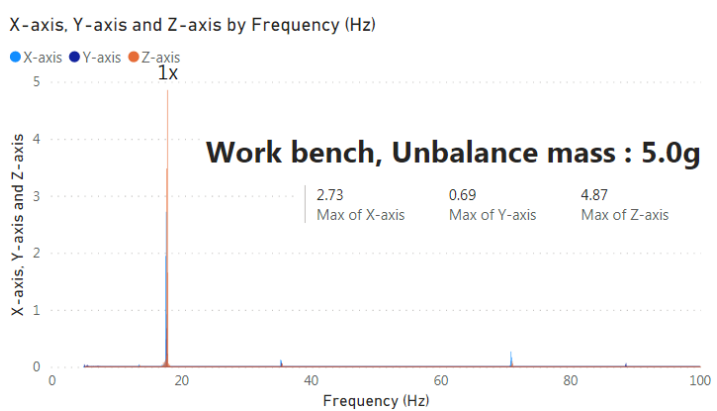

(d) unbalance mass $[5.0 \mathrm{~g}]$

Figure 4 Results of Vibration measurement in unbalance condition (@ Work bench set-up)

\subsection{Axis misalignment state result analysis}

In the state of axial misalignment, the distance between the rotation center of the motor shaft of the vibration simulator and the rotation center of the rotation shaft was tested under four conditions: $0.62[\mathrm{~mm}], 1.25[\mathrm{~mm}]$, 
$1.87[\mathrm{~mm}], 2.50[\mathrm{~mm}]$.

In the case of axial misalignment, unlike the case of mass unbalance, it is a fact that has been verified by many researchers that the $2 \mathrm{x}$ component is the main component instead of the $1 \mathrm{x}$ component.

As shown in [Figure 5], it was confirmed that axial misalignment state of the vibration simulator installed on the floor, the $2 x$ component appears larger than the $1 \mathrm{x}$ component in all other cases ([Figure. 5](b)(c)(d)) except the case where the axial misalignment distance is $0.62[\mathrm{~mm}] .[$ Figure. 5](a)

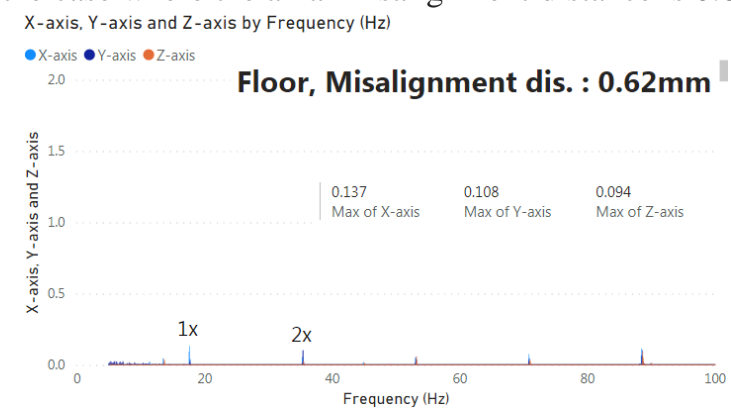

(a) Misalignment distance $0.62[\mathrm{~mm}]$

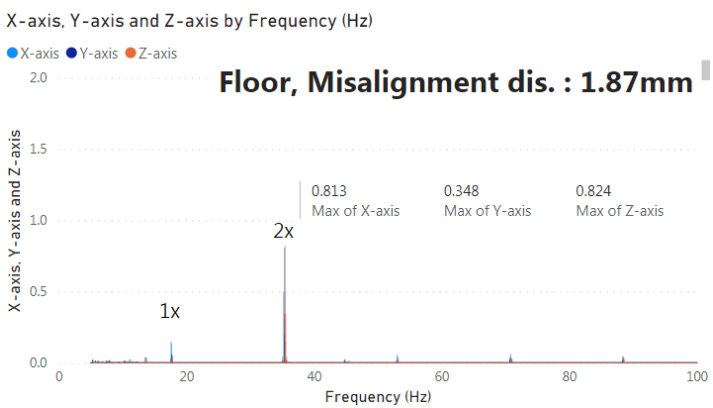

(c) Misalignment distance $1.87[\mathrm{~mm}]$
$X$-axis, Y-axis and Z-axis by Frequency (Hz)

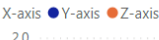

Floor, Misalignment dis. : $1.25 \mathrm{~mm}$

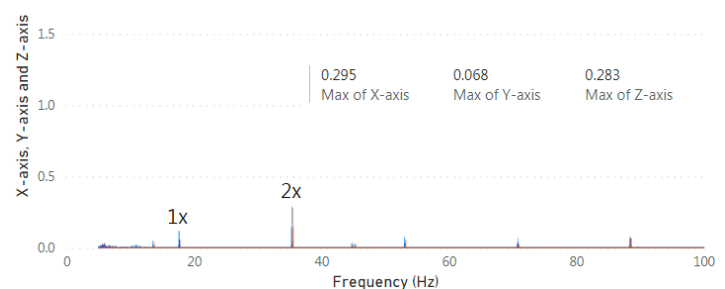

(b) Misalignment distance $1.25[\mathrm{~mm}]$

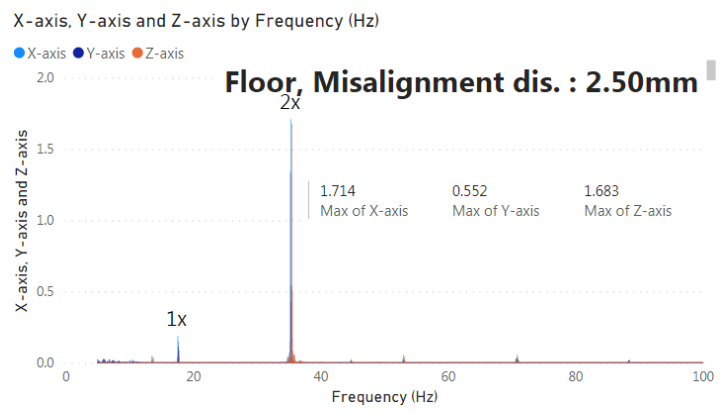

(d) Misalignment distance [2.50mm]

Figure 5 Results of Vibration measurement in misalignment condition (@ Floor set-up)

As shown in [Figure 6], in case of the vibration simulator is installed on the work bench, the 1x component is larger than the $2 \mathrm{x}$ component, except for the case where the axial misalignment distance is 2.50 [mm][Figure 6](d), confirming that the $1 \mathrm{x}$ component appears as the main component. [Figure 6] (a)(b)(c)

It was confirmed that in order to install the vibration simulator on the work bench and realize the axial misalignment state which the $2 \mathrm{x}$ component is measured as the main component, the axial misalignment distance of 2.50 [mm] or more must be set. [Figure 6] (d)

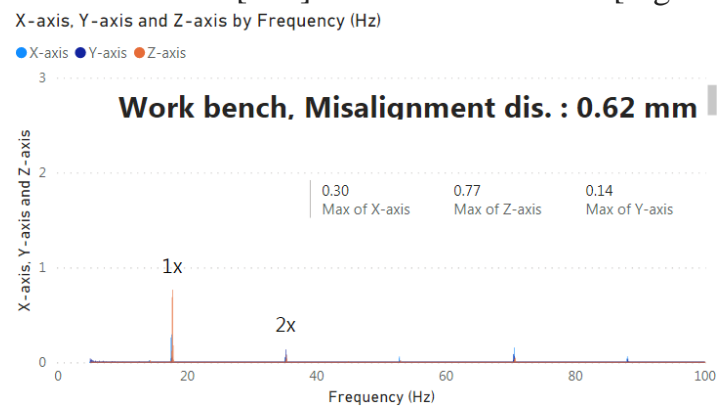

(a) Misalignment distance : $0.62 \mathrm{~mm}$

$X$-axis, $Y$-axis and $Z$-axis by Frequency $(H z)$

$\bullet X$-axis $\bullet$ - - -axis $\bullet Z$-axis

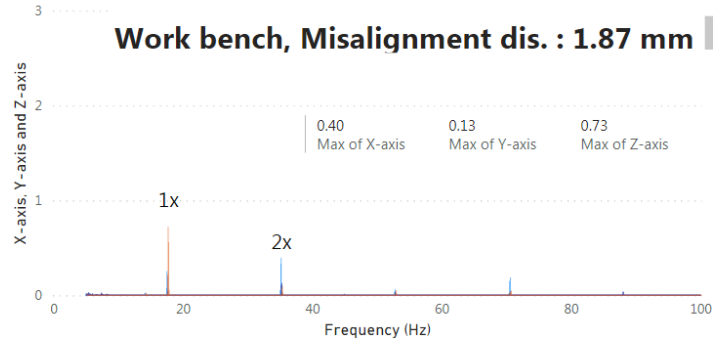

(c) Misalignment distance : $1.87 \mathrm{~mm}$
Work bench, Misalianment dis. : $1.25 \mathrm{~mm}$

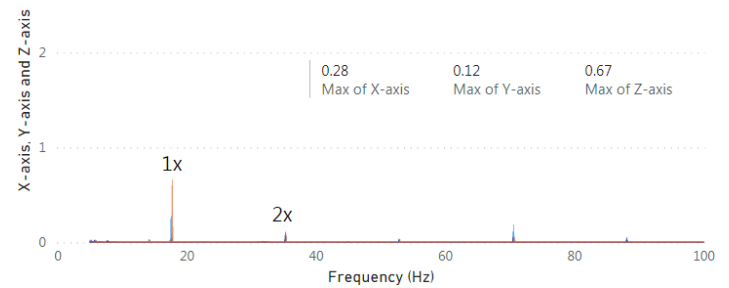

(b) Misalignment distance : $1.25 \mathrm{~mm}$

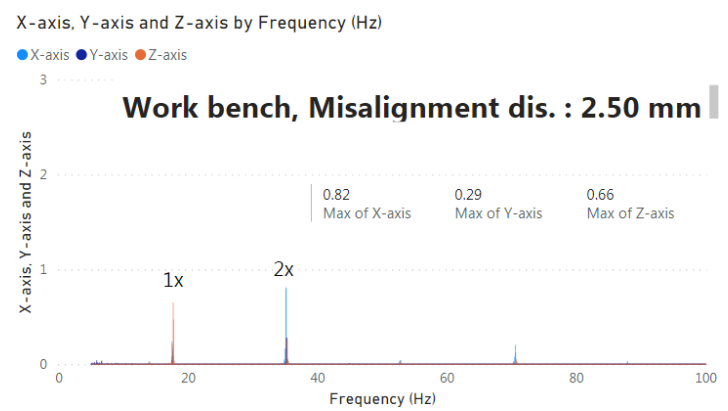

(d) Misalignment distance : $2.50 \mathrm{~mm}$

Figure 6 Results of Vibration measurement in misalignment condition (@ Work bench set-up) 


\subsection{Natural frequency of Work bench}

A bump test was conducted to check the natural frequency of the work bench where the vibration simulator was installed. The bump test is a method to check the natural frequency by measuring the vibration generated by giving an unknown shock to the system. It is a method commonly used in industrial sites to check the natural frequency of a facility.

As shown in [Figure 7], it was confirmed that the natural frequency of the work bench is identical at $17.5 \mathrm{~Hz}$, which is the rotational frequency of the vibration simulator, through the results of the bump test with the vibration simulator installed on the work bench.

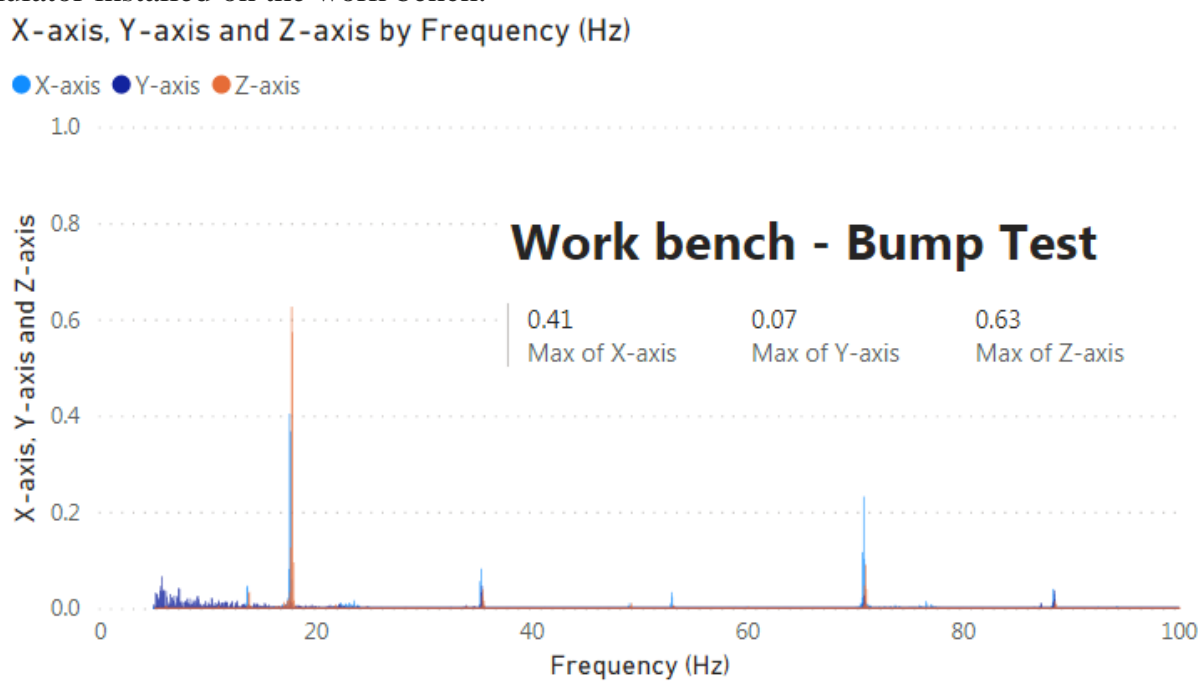

Figure 7 Bump Test Result of work bench (@ simulator set-up)

In case of natural frequency of the work bench where the vibration simulator is installed matches the rotation frequency of the motor, as shown in [Table 3], It was confirmed that a larger velocity value appeared than the addition of the $\mathrm{x}$ component 0.41 shown in the bump test.

Table 3 The result of Mass Unbalance condition

\begin{tabular}{cccc}
\hline \multirow{2}{*}{ Unbalance mass } & Floor & Work bench & \multirow{2}{*}{ Differences } \\
\cline { 2 - 3 } & max of x-axis & max of x-axis & \\
\hline $2.5[\mathrm{~g}]$ & 1.01 & 1.57 & $\triangle 0.56$ \\
\hline $3.0[\mathrm{~g}]$ & 1.15 & 1.84 & $\triangle 0.69$ \\
\hline $4.0[\mathrm{~g}]$ & 1.77 & 2.33 & $\triangle 0.56$ \\
\hline $5.0[\mathrm{~g}]$ & 1.96 & 2.73 & $\triangle 0.77$ \\
\hline
\end{tabular}

As shown in [Table 4], in the case of axial misalignment, the difference between the $2 \mathrm{x}$ and $1 \mathrm{x}$ values in the floor installation condition is in a proportional relationship as the axial misalignment distance increases. However, under the conditions of work bench installation, when the difference between $2 \mathrm{x}$ and $1 \mathrm{x}$ was $0.62[\mathrm{~mm}], 1.25[\mathrm{~mm}]$, and $1.87[\mathrm{~mm}], 1 \mathrm{x}$ was larger than $2 \mathrm{x}$. And it was confirmed that when the axial misalignment distance was $2.50[\mathrm{~mm}]$ or more, $2 \mathrm{x}$ was larger than $1 \mathrm{x}$. The fact that $2 \mathrm{x}$ is larger than $1 \mathrm{x}$ is a characteristic to be observed in the axial misalignment state.

Table 4 Test result of Misalignment condition

\begin{tabular}{ccccccc}
\hline \multirow{2}{*}{ Misalignment distance } & \multicolumn{3}{c}{ Floor, x-axis } & \multicolumn{3}{c}{ Work bench, x-axis } \\
\cline { 2 - 7 } & $\mathbf{1 x}$ & $\mathbf{2 x}$ & $\mathbf{2 x}-\mathbf{1 x}$ & $\mathbf{1 x}$ & $\mathbf{2 x}$ & $\mathbf{2 x - 1 x}$ \\
\hline $0.62[\mathrm{~mm}]$ & 0.137 & 0.061 & -0.076 & 0.300 & 0.062 & -0.238 \\
\hline $1.25[\mathrm{~mm}]$ & 0.123 & 0.295 & 0.172 & 0.283 & 0.081 & -0.202 \\
\hline $1.87[\mathrm{~mm}]$ & 0.156 & 0.813 & 0.657 & 0.260 & 0.040 & -0.22 \\
\hline $2.50[\mathrm{~mm}]$ & 0.194 & 1.714 & 1.52 & 0.246 & 0.818 & 0.572 \\
\hline
\end{tabular}

In general, vibration simulator manufacturers perform the setting of a normal state, mass unbalance state, and axial misalignment state at the most ideal installation condition, such as a floor or a surface plate with very 
high rigidity. However, when installed at an educational site, vibration simulators are often installed on work benches with insufficient rigidity, so accurate vibration measurements cannot be made.

In particular, in order to show the state where the main component to be observed in the axial misalignment state is $2 \mathrm{x}$, the axial misalignment distance is excessively set, which is the cause of the failure of the vibration simulator in the long term.

\section{Results and Discussion}

Through the experiment presented in this paper, it was confirmed that the installation conditions of the vibration simulator effect to the vibration data. In actual training sites, installation is performed under various installation conditions without an installation guide being presented. Therefore, for proper training, the influence of the installation conditions on the measured vibration data must be considered. In addition, it should be considered that the influence of the installation conditions is subdivided and the influence on each condition is calculated mathematically.

\section{Conclusion}

In educational sites, vibration simulators are often installed on work benches with insufficient rigidity, and consideration for this has not been sufficiently made. In this study, in case of vibration simulator is used in an educational field, how the installation conditions effect to the vibration simulator and measured value, and for the correct installation of the vibration simulator, the following conditions are checked and installed.

a) Check the natural frequency of the work bench to be installed through the bump test.

b) If the natural frequency of the work bench and the rotational frequency match,

(1) Change the natural frequency of the work bench,

- Use of work bench with high rigidity

- Attach stiffener to work bench

- Attach the mass to the work bench

(2) Change the vibration simulation rotation frequency.

As interest in vibration facility diagnosis increases, the demand for vibration simulators for facility diagnosis education will also increase. Through this paper, it is expected that the training of correct vibration facility diagnosis will be provided through the installation and use of appropriate vibration simulation considering the effect of installation conditions.

\section{References}

1. Rosmaini Ahmad, Shahrul Kamaruddin. An overview of time-based and condition-based maintenance in industrial application. Computers \& Industrial Engineering. 2012; 63(1);135-149.

2. Andrew LS, Daming Lin, Dragan Banjevic. A review on machinery diagnostics and prognostics implementing condition-based maintenance. Mechanical Systems and Signal Processing. 2006;20(7); 1483-1510.

3. Bernd Bauer, Bernd Geropp, Andreas Seeliger. Condition Monitoring and Predictive Maintenance in Mining Industry Using Vibration Analysis for Diagnosis of Gear Boxes. IFAC Proceedings Volumes. 1997;30(18):989-992.

4. Sadettin Orhana, Nizami Aktürkb, Veli Çelika. Vibration monitoring for defect diagnosis of rolling element bearings as a predictive maintenance tool. NDT \& E International. 2006;39(4):293-8.

5. Amandeep Singh, Anand Parey. Gearbox fault diagnosis under non-stationary conditions with independent angular re-sampling technique applied to vibration and sound emission signals. Applied Acoustics. 2019;144(15); 11-22.

6. Vaggeeram H, PSS. srinivasan. Vibration analysis of parallel misaligned shaft with ball bearing system. Indian Journal of Science and Technology. 2009;2(9):61-8.

7. Deepak P. Hujare, Madhuri G. Karnik. Vibration response of parallel misalignment in Al shaft rotor bearing system with rigid coupling. 2018;5(11):23863-23871

8. Choong-Hwi Lee, Hyoun Jin Sim, Jae-Eung Oh, Lee Jung Yoon. Development of the Fault Diagnostic System on the Rotating Machinery Using Vibration Signal. Korean Society for Precision Engineering. 2004;21(12):54-9

9. Susto, G. A., Schirru, A., Pampuri, S., McLoone, S., \& Beghi, A. Machine Learning for Predictive Maintenance: A Multiple Classifier Approach. IEEE, 2014 Aug;11(3):812-20

10. Zhiqiang Chen, Xudong Chen, Chuan Li, René-Vinicio Sanchez, Huafeng Qin. Vibration-based gearbox fault diagnosis using deep neural networks. Journal of Vibroengineering, 2017;19(4):2475-96

11. Cyril M. Harris, Allan G. Piersol, HARRIS's SHOCK AND VIBRATION HANDBOOK. $5^{\text {th }}$ ed. NewYork:McGraw-Hill;2002;p.14.11 